\title{
Economics reasons for unemployment of college students
}

\author{
YU LIU \\ School of Economics and Management, Shenyang Aerospace University, Shenyang, 110136, \\ China \\ E-mail: 43925702@qq.com
}

Keywords: Economics; Unemployment of college students; Structural unemployment; Frictional unemployment; Voluntary unemployment; Employment guidance

\begin{abstract}
In recent years, with the increasingly growing enrollment of college students, it is becoming more and more difficult for students to get employed. The study on reasons for the unemployment issue of college students is of great importance and urgency under the current background of increasingly serious employment situation. In this paper, the author will briefly introduce the employment of college graduates in the past three years in China, and then economically describe and analyze the reasons for the unemployment of college students from aspects: structural unemployment, frictional unemployment and voluntary unemployment. On this basis, the author proposes a resolution to the problem of students' unemployment: to optimize the education system in colleges, and to establish a scientific training mechanism; to change students' concept of employment, and to improve students' employability; also, to broaden students' horizons of employment, and to encourage them to start their own businesses.
\end{abstract}

\section{Foreword}

With the continuous increase in enrollment of China's university in recent years, the graduates' employment has become an unavoidable problem for society, schools, and students. According to Ministry of Education, the total number of graduates in the last three years 2010, 2011 and 2012 were approximately 6.3 million, 6.6 million and 6.8 million, the of spurting growth of graduates greatly raise the difficulty for the employment of college graduates. Whether or not these graduates can get employed will not only directly affect their own personal life and career prospects, also to some extent reflect the teaching standards and the quality of current higher education, and relate to the benign sustained progress of Higher Education. More importantly, too many unemployed college graduates will cause various problems, which will bring a direct impact on the construction and development of a harmonious society in China. Therefore at this stage, the profound analysis about reasons for unemployment of China's college students and the proposal of positive scientific countermeasures will have great practical significance.

\section{Definition of unemployment of college students}

\subsection{Definition of unemployment}

According to the ILO (International Labor Organization), unemployment means a person above a certain age, with the ability to work, cannot be employed during the given time or fail to work a required period, and is still looking for paid work. Unemployment is a state where laborers with the ability and the will to work do not have jobs, caused by the total imbalance between labor supply and demand for labor or by structural imbalance, and its essence is that workers cannot be combined with production materials to create social wealth.

\subsection{Definition of unemployment of college students}

Unemployed persons are generally required to meet three basic conditions: Firstly, they do not have a job during the survey time. Secondly, they are of the proper age and able to work. Thirdly, they are willing to work.[1] 
In accordance with the definition of unemployment, the unemployment of university graduates only meets the two basic conditions of unemployment; many unemployed college students do not meet the third condition, that is, they are able to work, but they choose not to work. Those people may have been employed, but they are not willing to find a job because they want to get higher salary, or they plan to go abroad or for other personal reasons. Therefore, those people cannot be called as the unemployed people. Obviously, the general unemployment is different from the unemployment of college graduates discussed in this article. The unemployed college students referred to in this article contain two types: in one type, college graduates above a certain age, with the ability and will to work, cannot be employed during the given time, and is still looking for paid work; in other type, college graduates above a certain age, with the ability to work, cannot be employed during the given time, and choose not to work.

\section{Economics reasons for unemployment of college students}

According to macroeconomics, unemployment is divided into structural unemployment, frictional unemployment and cyclical unemployment or voluntary unemployment.

2.1 Structural unemployment causes the structural mismatch between labor supply and employer's demand.

According to macroeconomics, the structural unemployment is defined as the unemployment caused by the mismatch between labor supply and demand, which is characterized by the coexistence of both unemployment and job vacancy. The unemployed do not have the right skills or proper place of residence, so they cannot match with the existing job vacancies.

The essence of college students failing to get employed is that an economic society needs a large number of practical talents with some theoretical knowledge and mastered with an operation and skills; college students are mostly looking for the first job of their life, so it is difficult for them to meet the actual needs of the employer, that is, there is a mismatch between the actual human capital supply and employer's demand structure, resulting in an employability gap between the supply and demand in the labor market, [2] thus forming the structural unemployment, "job without a person" or "person without a job".

2.2 Frictional unemployment leads to asymmetry between information of labor supply and demand

Frictional unemployment is a phenomenon when job-seekers keep going to the labor market once and again in order to find a satisfactory job due to the insufficient information in the labor market [3]. According to job seeking and matching theory, a new college graduate is not fully aware of the employment information of the labor market, but he would expect to find a job with the best salary, so he has to spend time in constantly seeking jobs. At any time point, some new jobs are created in the labor market, which is a supply-demand matching process. In this process, the graduates will be faced with this choice: when the marginal revenue for job seeking is greater than its marginal cost, then they shall continue seeking; when the marginal revenue cannot cover the marginal cost, they shall stop seeking.

\subsection{Voluntary unemployment and dual labor market}

In addition to the above three types of unemployment, in macroeconomics there are another pair of unemployment, the so-called voluntary unemployment and involuntary unemployment. The former refers to the unemployment formed when job seekers are unwilling to accept the current wage level, while the latter refers to the unemployment formed when job seekers are willing to accept the prevailing wage, but still cannot find a job.

In China, a developing country, the vast majority of unemployed university graduates fall into the voluntary unemployment, that is, in fact, these college students are unemployed not because they cannot find a job, but for some higher expectations. Specifically, the reasons are as follows: 
China's labor market has the typical characteristics of the dual structure, due to such constraints as the level of economic development, system design, etc. On the one hand, in the primary labor market, workers can have good working environment, high salary, stable employment, more training and promotion opportunities, and also a sound social security; on the other hand, in the secondary labor market, workers will have poor working conditions, low salary, volatile employment, few training and promotion opportunities, and bad social security (some employers will not even provide basic insurance). Therefore, voluntary unemployment becomes university graduates' another "investment", because college students who spend a lot of tuition for investment in human capital are often willing to endure longer unemployment duration and the unemployment rate in exchange for lifelong-benefit employment in the labor market.

In summary, structural unemployment, frictional unemployment and voluntary unemployment are the main reasons for China's college students failed to timely get employed after graduation. Facing with an increasing group of university graduates, it is urgent to solve the employment problem for them.

\section{Solution to the unemployment of college students}

\subsection{Optimize the higher education system, establish a scientific training mechanism}

Colleges should set their departments according to market demands, actively promote the deep reformation of personnel training patterns, take the initiative to adapt the development of market economy (arranging "production" as "need" decides), strengthen the graduates' ability to adapt to the market and employability competitiveness, and finally reach a structural balance of supply and demand for university graduates on the market enhanced graduates. Specifically, we can take the following three measures: First of all, adjust the professional setting according to the market demand. Build an employment tracking mechanism to track whether students can do a job after graduation using all or at least part of what they have learned in university, rather than only keep eyes on the employment rate and then decide whether or not one master is scientific. Secondly, reasonably adjust the university's teaching and training plan. It is of very important significance to scientifically adjust the training plan and arrange some courses in advance, by which graduates can actively grasp the job-seeking golden time to find high-quality jobs. Last but not the least, improve the timeliness of the Student Career Guidance. Firstly, set a specialized guidance institution, having specialized career guidance. Secondly, establish dynamic employment guidance, having throughout career guidance. Thirdly, enrich the employment guidance forms, having multi-faceted employment guidance.

\subsection{Change students' concept of employment, improve students' employability.}

To promote the employment of university students, we shall enhance graduates' employability. Employability refers to a person's ability to find a job, keep his job and do the job well, gained via learning process. To improve the college students' employability, we shall do the following points: Firstly, cultivate students' initiative employability, and help students to objectively analyze the current employment situation, to change the old employment concept of "waiting, relying and asking", and to actively seize employment opportunities. Secondly, cultivate students' professional employability; in addition to the basic professional knowledge, we shall also teach students excellent professional skills and high level of computer and foreign language ability. Thirdly, teach students how to adapt to employment; with the help of social practice, improve their organization and coordination skills, stress tolerance, interpersonal skills, etc. Also, we can also make them understand the employment environment, policies and situation, which is helpful for them to find a job matching with their knowledge level, character, ability and quality.

\subsection{Broaden students' employment horizons, encourage students to start their own businesses}

As high-quality human resources, college students are not only job seekers, but also creators of new jobs. Since they have good personal qualities and professional knowledge, opening their own 
businesses, will not only to lower the unemployment rate, but also accelerate the conversion of the results from the new technology industry. Currently, less than $2 \%$ of China's college graduates start their own businesses, while this rate reaches 20\% [4] in the United States, Japan and many other countries. From this, we can see the great potential of Chinese university graduates' starting their own businesses. More meaningfully, university graduates' starting their own businesses not only can solve their own employment problems, but also may create more employment opportunities for the society [5].

In order to better motivate college students to start their own business, we must first cultivate their awareness of entrepreneurship and entrepreneurial spirit. Firstly, by taking a variety of ways, guide and encourage students to participate in the "Challenge Cup" and other entrepreneurship competitions during years in college, to stimulate their interest in their own businesses. Secondly, increase investment in entrepreneurship education and optimize the entrepreneurial environment. Establish the Technology Venture Fund for college students, and provide small low-interest loans or subsidized loans for graduates with entrepreneurial intention and entrepreneurial new technology projects or achievements, improve necessary support measures, regulations and policies protection for students' business starting, and strengthen the construction of college students' venture base.

\section{References}

[1] YY. WU, 'Transition of college students employment policies and countermeasures', Guangzhou: Guangdong Higher Education Press, 2009.

[2] T. Wang, XQ. Zeng, 'University Graduates' structural unemployment reason and countermeasure research’, Education and economic, pp. 1-4, 2009 (1).

[3] ZG. BAO, EJ. JIANG, 'College Students' occupation decision difficult mental intervention paths’, Journal of Ideological \& Theoretical Education, pp. 105-108, 2011 (3).

[4] DS. LAI, 'Allow more workers to become entrepreneurs', China's reform (Comprehensive version ), pp. 68-70, 2008 (2).

[5] C. XIANG, JS. LEI, 'University students' entrepreneurial attitudes and tendencies relationship and influencing factors', Research on education of Tsinghua University, pp. 117-124, 2011,32 (5). 